\title{
Effect of diabetes on early and late survival after isolated first coronary bypass surgery in multivessel disease
}

\author{
Antonio Maria Calafiore, MD \\ Michele Di Mauro, MD \\ Gabriele Di Giammarco, MD \\ Marco Contini, MD \\ Giuseppe Vitolla, MD \\ Angela Lorena lacò, MD \\ Carlo Canosa, MD \\ Stefano D'Alessandro, MD
}

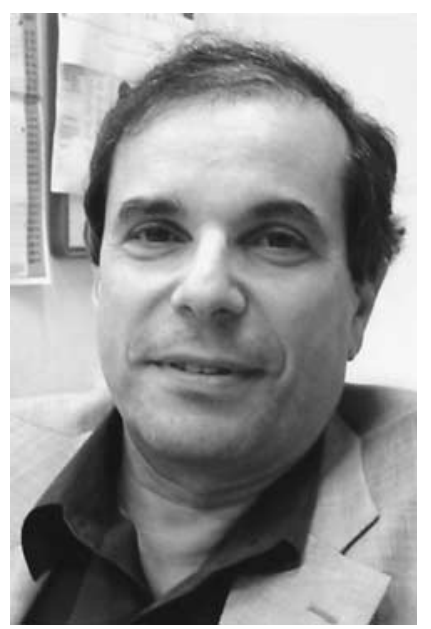

Dr Calafiore

From the Department of Cardiology and Cardiac Surgery, University "G. D’Annunzio," Chieti, Italy.

Received for publication Aug 2, 2001; revisions requested Oct 1, 2001; revisions received May 7, 2002; accepted for publication May 16, 2002.

Address for reprints: Antonio Maria Calafiore, MD, "G. D’Annunzio" University Division of Cardiac Surgery c/o S. Camillo de' Lellis Hospital via C. Forlanini, 50, 66100 Chieti, Italy (E-mail: calafiore@ unich.it).

J Thorac Cardiovasc Surg 2003;125:144-54

Copyright $(\odot 2003$ by The American Association for Thoracic Surgery

$0022-5223 / 2003 \$ 30.00+0$

doi: $10.1067 / \mathrm{mtc} .2003 .73$
Objective: Diabetes has not yet been investigated as a risk factor for early and late cardiac-related death.

Methods: Patients operated on from January 1988 to December 1999 were considered; 767 were diabetic (group D) and 2593 were nondiabetic (group ND). Patients with preoperative hemodynamic deterioration were excluded. Early (30-day) mortality (any causes and cardiac causes) was evaluated with univariate analysis and stepwise logistic regression. Ten-year actuarial freedom from death of any cause and cardiac death was also assessed with univariate and Cox analyses.

Results: Early mortality was $2.2 \%$ (group D, $3.3 \%$; group ND, $1.9 \% ; P=.023$ ). Early cardiac mortality was $1.3 \%$ (group D, $2.2 \%$; group ND, $1.1 \% ; P=.0016$ ). Diabetes was an independent risk factor only for cardiac death and not for death of any cause. Five-year survival was $93.5 \% \pm 0.5 \%$ (group D, $92.5 \% \pm 1.1 \%$; group ND, $93.9 \% \pm 0.6 \% ; P=.0304)$. Diabetes was not an independent risk factor. Five-year freedom for cardiac death was $96.3 \% \pm 0.4 \%$ (group D, $94.9 \% \pm 0.9 \%$; group ND, $96.6 \% \pm 0.4 \% ; P=.0155$ ). Diabetes was an independent risk factor. However, if only the patients who survived the first 30 days are considered, diabetes disappears as a risk factor (5-year freedom for cardiac death, $97.8 \% \pm 0.3 \%$; group $\mathrm{D}, 97.3 \% \pm 0.8 \%$; group ND, $97.9 \% \pm 0.4 \% ; P=0.2389)$.

Conclusions: Diabetes is an independent risk factor for early cardiac death only. Long-term survival in patients who survive the first 30 days is not statistically significantly different for diabetic and nondiabetic patients. In fact, the rates appear very similar.

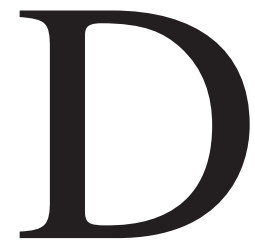

iabetes is a widely recognized risk factor for increased early and late mortality after myocardial revascularization in patients with multivessel disease. ${ }^{1-17}$ Even if better results after coronary artery bypass grafting $(\mathrm{CABG})$ than after percutaneous transluminal coronary angioplasty had been demonstrated in the Bypass Angioplasty Revascularization Investigation trial, ${ }^{1}$ further studies were not able to confirm this finding. ${ }^{13,14}$ Therefore it seems that diabetes is a risk factor independent from the strategy used. However, in other studies diabetes seems to be weakly related to higher early and late mortality after CABG, ${ }^{15-22}$ leaving the problem open to further evaluation.

During the past decade, different surgical techniques, such as normothermic perfusion, ${ }^{23} \mathrm{CABG}$ on a beating heart without cardiopulmonary bypass $(\mathrm{CPB}),{ }^{24,25}$ and extensive use of arterial conduits, ${ }^{26,27}$ became popular. We reviewed our 
TABLE 1. Preoperative data in diabetic (group D) and nondiabetic (group ND) patients

\begin{tabular}{|c|c|c|c|}
\hline & $\begin{array}{l}\text { Group ND } \\
(\mathrm{n}=2593)\end{array}$ & $\begin{array}{c}\text { Group D } \\
(n=767)\end{array}$ & $P$ value \\
\hline Age (y) & $62.0 \pm 9.5$ & $63.2 \pm 8.8$ & .001 \\
\hline$\geq 75$ & $217(8.4 \%)$ & $58(7.6 \%)$ & .474 \\
\hline $\mathrm{EF}(\%)$ & $59.1 \pm 12.9$ & $57.0 \pm 14.0$ & $<.001$ \\
\hline$\leq 35$ & $133(5.1 \%)$ & $62(8.1 \%)$ & .002 \\
\hline Female sex & $327(12.6 \%)$ & $206(26.9 \%)$ & $<.001$ \\
\hline Urgent & $678(26.1 \%)$ & $209(27.2 \%)$ & .543 \\
\hline Left main & $309(11.9 \%)$ & $88(11.5 \%)$ & .817 \\
\hline Hypertension & $1133(43.7 \%)$ & $402(52.4 \%)$ & $<.001$ \\
\hline Previous AMI & $1445(55.7 \%)$ & $454(59.2 \%)$ & .407 \\
\hline Carotid disease & $278(10.7 \%)$ & $128(16.7 \%)$ & $<.001$ \\
\hline CRF $(\mathrm{cr} \geq 2.0 \mathrm{mg} / \mathrm{dL})$ & $38(1.5 \%)$ & $14(1.8 \%)$ & .478 \\
\hline $\mathrm{CHF}$ & $49(1.9 \%)$ & $23(3.0 \%)$ & .062 \\
\hline
\end{tabular}

$E F$, Ejection fraction; $A M I$, acute myocardial infarction; $C R F$, chronic renal failure; $c r$, creatininemia; $C H F$, chronic heart failure.

experience in patients with multivessel coronary disease who underwent surgical revascularization during a 12-year period to evaluate (1) whether diabetes is a risk factor for early or late survival and, if so, (2) whether there is any technical factor that can improve survival in diabetic patients.

\section{Methods}

From January 1988 to December 1999, 3392 patients with multivessel disease underwent first isolated surgical myocardial revascularization. Thirty-two patients who had preoperative low-output syndrome were not included because their status could influence the early outcome more than any other risk factor. Globally, 3360 patients were entered into this study. Among them, 767 patients $(22.8 \%)$ were diabetic (group D) and receiving oral (group OT, $\mathrm{n}=596[77.7 \%]$ ) or insulin (group IT, $\mathrm{n}=171$ [22.3\%]) treatment, and 2593 (77.2\%) were nondiabetic (group ND). Patients on diet because of mild fasting hyperglycemia were considered in group ND. Table 1 shows some of the preoperative characteristics of both groups.

\section{Surgical Details}

CPB was used in 2181 (65.4\%) patients and not used in 1179 $(34.6 \%)$ patients. Perioperative technical data are shown in Table 2. Simultaneous carotid endoarterectomy was performed in 65 patients $(1.9 \% ; 47$ [1.8\%] in group ND and 18 [2.3\%] in group D; $P=.345)$.

\section{Postoperative Course}

After the operation, all the patients were admitted to the intensive care unit and later sent to the regular ward. They were then followed up at our outpatient clinic. The follow-up deadline was June 30, 2000. Recent information about their clinical status was obtained directly from the referring physician or by telephone. Mean follow-up was $50 \pm 38$ months (median, 41 months; minimum, 3 months; maximum, 150 months; 25th percentile, 20 months; 75 th percentiles, 67 months), $43 \pm 34$ months in diabetic patients (median, 33 months; minimum, 3 months; maximum, 149 months; 25th percentile, 17 months; 75 th percentile, 67 months), and $53 \pm 39$ months in nondiabetic patients (median, 44 months; minimum, 3 months; maximum, 150 months; 25 th percentile, 21 months; 75th percentile, 72 months; $P<.001$ ). Follow-up was $98.9 \%$ completed.

\section{Study Method}

The real survival at 30 days after the operation was analyzed by using a variety of risk factors (appendix). Patients were first considered as a whole; as a second step, rates were given overall and by diabetes group to illustrate the association of factors on outcomes within the patients in groups D and ND.

The same variables were used to analyze 5-year actuarial survival, inclusive of the first month, for all patients. As a second step, the first month was withdrawn from the analysis, and the 5-year survival of patients who survived 1 month was evaluated to explore the weight of early mortality on late survival. All the analyses were repeated to evaluate the influence of diabetes on freedom from cardiac death. When some perioperative surgical strategies were evaluated, survival and freedom from cardiac death were considered at 10 years.

\section{Definitions of Terms}

Need of inotropic agents was defined as infusion of greater than 5 $\mu \mathrm{g} \cdot \mathrm{kg}^{-1} \cdot \min ^{-1}$ dobutamine or any dose of epinephrine or norepinephrine for more than 12 hours.

Cerebrovascular accident (CVA) was defined as global or focal neurologic deficit lasting less (transient ischemic attack) or more (stroke) than 24 hours that could be evident after emergence from anesthesia or after first awaking without any neurologic deficits. CVA was diagnosed by a neurologist and confirmed with a brain computed tomographic scan.

Acute myocardial infarction was defined as enzymatic elevation, electrocardiographic signs of necrosis, new akinetic segments at echocardiography, and non- $\mathrm{K}^{+}$-related ventricular arrhythmias.

Acute renal failure was defined as a postoperative creatinine value of greater than $2.0 \mathrm{mg} / \mathrm{dL}$ for more than 24 hours if the preoperative value was less than $1.4 \mathrm{mg} / \mathrm{dL}$ or a 1 -unit creatinine increase if the preoperative value was greater than $2.0 \mathrm{mg} / \mathrm{dL}$.

Early major events were defined as the sum of death of any cause, CVA, acute myocardial infarction, low-output syndrome (defined as need for an intra-aortic balloon pump, inotropic drugs 
TABLE 2. Operative data according to groups ND and D

\begin{tabular}{lccc}
\hline & $\begin{array}{c}\text { Group ND } \\
\text { (n = 2593) }\end{array}$ & $\begin{array}{c}\text { Group D } \\
\text { (n = 767) }\end{array}$ & P value \\
\hline CPB & $1699(65.5 \%)$ & $482(62.8 \%)$ & .174 \\
Anastomoses/patient & $2.6 \pm 1.1$ & $2.6 \pm 1.0$ & .949 \\
LITA & $2351(90.7 \%)$ & $717(93.5 \%)$ & .015 \\
RITA & $1210(46.7 \%)$ & $352(45.9 \%)$ & .707 \\
RGEA & $359(13.8 \%)$ & $97(12.6 \%)$ & .395 \\
RA & $200(7.7 \%)$ & $53(6.9 \%)$ & .459 \\
IEA & $107(4.1 \%)$ & $18(2.3 \%)$ & .022 \\
SVG & $1045(40.3 \%)$ & $326(42.5 \%)$ & .276 \\
BITA & $1178(45.4 \%)$ & $346(45.1 \%)$ & .876 \\
SVG to LAD & $230(8.9 \%)$ & $53(6.9 \%)$ & .086 \\
TAMR & $1093(42.2 \%)$ & $308(40.2 \%)$ & .325 \\
\hline
\end{tabular}

LITA, Left internal thoracic artery; RITA, right internal thoracic artery; RGEA, right gastroepiploic artery; RA, radial artery; IEA, inferior epigastric artery; $B I T A$, bilateral internal thoracic artery; TAMR, total arterial myocardial revascularization.

TABLE 3. Early postoperative data according to groups ND and $D$

\begin{tabular}{lccc}
\hline & $\begin{array}{c}\text { Group ND } \\
\text { (n = 2593) }\end{array}$ & $\begin{array}{c}\text { Group D } \\
\text { (n= 767) }\end{array}$ & P value \\
\hline Deaths & $49(1.9 \%)$ & $25(3.3 \%)$ & .023 \\
CVA & $29(2.1 \%)$ & $8(1.0 \%)$ & .861 \\
AMI & $23(0.9 \%)$ & $8(1.0 \%)$ & .089 \\
Inotropes & $57(2.2 \%)$ & $26(3.4 \%)$ & .065 \\
IABP & $14(0.5 \%)$ & $7(0.9 \%)$ & .370 \\
Transfused patients & $549(21.2 \%)$ & $189(24.6 \%)$ & .041 \\
CK-MB peak & $38.8 \pm 59.0$ & $34.6 \pm 46.7$ & .089 \\
ICU stay (h) & $22.2 \pm 21.6$ & $20.8 \pm 24.4$ & .142 \\
Hospital stay (d) & $5.7 \pm 5.2$ & $5.4 \pm 4.9$ & .123 \\
\hline
\end{tabular}

$A M I$, Acute myocardial infarction; IABP, intra-aortic balloon pump; $C K-M B$, creatine kinase muscle and brain; $I C U$, intensive care unit.

for $>12$ hours, or both), need for mechanical ventilation for more than 24 hours in the absence of low-output syndrome, acute renal insufficiency (defined as blood creatinine level $>2.0 \mathrm{mg} / \mathrm{dL}$ and 2 times the preoperative value), or acute renal failure (need for ultrafiltration without a related operation), gastrointestinal complications with or without related surgery.

Cardiac death was defined as any cardiac-related death, sudden and unknown.

\section{Statistical Analysis}

All continuos variables were expressed as means \pm SD. Groups were compared by means of unpaired 2-tailed $t$ testing in case of normally distributed factors, whereas Mann-Whitney tests were used in case of nonnormally distributed variables, and $\chi^{2}$ tests (Pearson $\chi^{2}$ and Fisher exact tests) were used for categoric variables. Stepwise logistic regression was used to select the independent variables that could predict death of any cause. Actuarial survival curves were obtained with the Kaplan-Meier method. Statistical significance was calculated with the log-rank test. Cox analysis was used to evaluate the independent risk factors for reduced late survival. All the multivariable analysis included univariate variables with $P$ values of less than .2 . Results of stepwise logistic regression were expressed as odds ratios with associated
95\% confidence limits and $P$ values. Results of Cox analysis were expressed as hazard ratios, $95 \%$ confidence limits, and $P$ values. The SPSS software (SPSS, Chicago, Ill) was used for all analyses in this study.

\section{Results}

\section{Early Mortality}

During the first 30 days after the operation, 72 (2.2\%) patients died, 25 (3.3\%) in group D and 49 (1.9\%) in group ND $(P=.023)$. Table 3 summarizes the postoperative data. The results of stepwise logistic regression are shown in Table 4. Diabetes was not a risk factor for higher 30-day mortality.

The incidence of cardiac-related 30-day mortality was $1.3 \%$ (45 patients), $2.2 \%$ (17 patients) in group D and $1.1 \%$ (28 patients) in group ND $(P=.016)$. The incidence of cardiac deaths was higher in group D (17/25 [68.0\%]) than in group ND (28/49 [57.1\%]) but not significantly $(P=$ .511). Results of stepwise logistic regression are also summarized in Table 4. The analysis showed that diabetes was an independent factor for increased 30-day cardiac-related mortality. Again, early survival was not influenced by any technical aspect.

\section{Late Actuarial Survival}

During the follow-up period, 137 (4.1\%) patients died, 32 (4.2\%) in group D and 105 (4.0\%) in group ND. Five-year overall actuarial survival, first month included, was $93.5 \%$ $\pm 0.5 \%, 93.9 \% \pm 0.6 \%$ in group ND and $92.5 \% \pm 1.1 \%$ in group $\mathrm{D}(P=.0304$, Figure 1$)$. Table 5 shows the independent predictors of lower survival at the Cox analysis. Diabetes was not an independent predictor of higher late mortality.

Seventy-three (2.2\%) patients died of cardiac causes, 20 $(2.6 \%)$ in group D and $53(2.0 \%)$ in group ND. The incidence for cardiac death was higher in group D (20/32 [62.5\%]) than in group ND (53/105 [50.5\%]). Freedom from cardiac death, first month included, was $96.3 \% \pm$ 


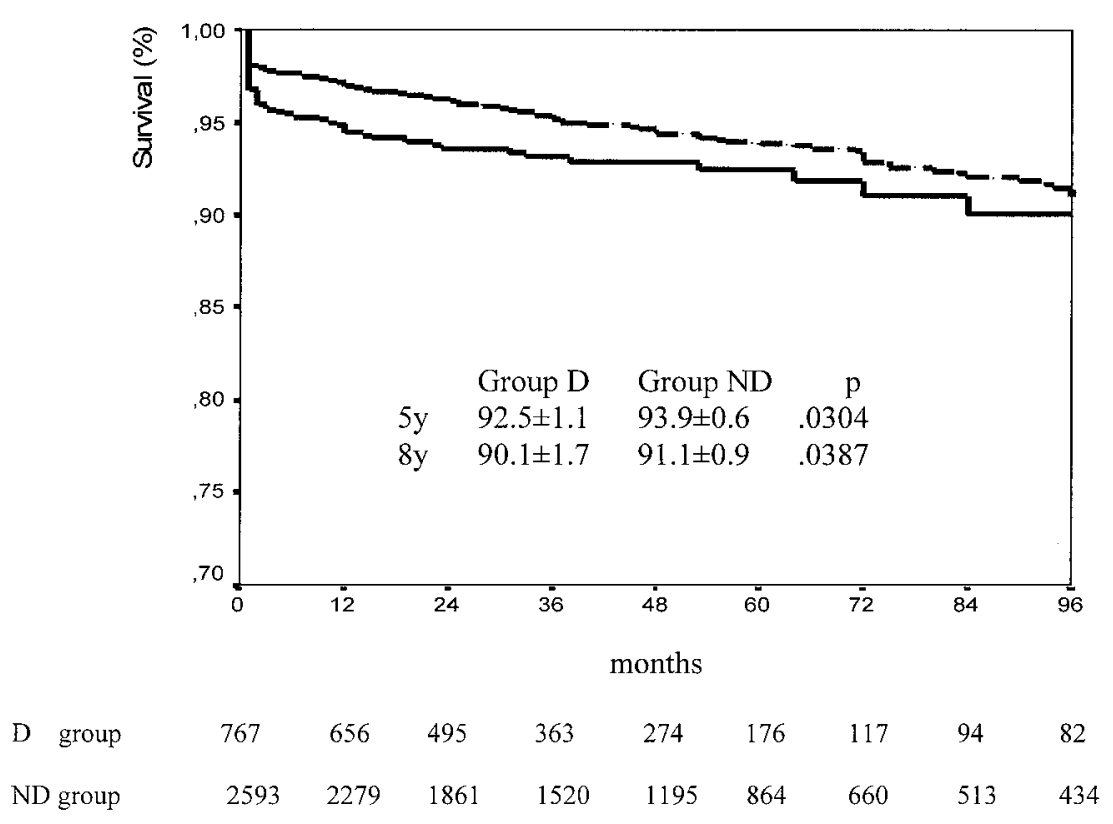

Figure 1. Five-year actuarial survival (first month included): group D (solid line) versus group ND (dashed line).

TABLE 4. Stepwise logistic regression: Independent risk factors for increased early mortality, any death, and cardiac deaths

\begin{tabular}{|c|c|c|c|c|c|c|}
\hline \multirow[b]{2}{*}{ Variable } & \multicolumn{3}{|c|}{ Any death } & \multicolumn{3}{|c|}{ Cardiac deaths } \\
\hline & $\begin{array}{l}\text { All patients, OR } \\
\text { (95\%CL) }\end{array}$ & $\begin{array}{l}\text { Group D, OR } \\
\text { (95\%CL) }\end{array}$ & $\begin{array}{l}\text { Group ND, } \\
\text { OR (95\%CL) }\end{array}$ & $\begin{array}{c}\text { All patients, OR } \\
\text { (95\%CL) }\end{array}$ & $\begin{array}{l}\text { Group D, OR } \\
\text { (95\%CL) }\end{array}$ & $\begin{array}{l}\text { Group ND, } \\
\text { OR (95\%CL) }\end{array}$ \\
\hline Untouchable ascending aorta & $2.9(1.3-6.8) P=.0116$ & $2.1(0.5-8.3)$ & $3.5(1.2-10.3)$ & $1.9(0.8-4.2) P=.1545$ & $1.7(0.5-6.2)$ & $2.0(0.7-6.0)$ \\
\hline Carotid diseas & $2.1(1.2-3.7) P=.0107$ & .0) & & $1.2(0.7-2.0) P=.3324$ & & $6-2.3)$ \\
\hline$E F \leq 35 \%$ & $2.2(1.1-4.5) P=.0250$ & $8.2(0.9-3.8)$ & $3.0(1.3-6.9)$ & $2.0(1.1-3.6) P=.2598$ & $1.6(0.6-4.4)$ & $2.0(0.98-4.2)$ \\
\hline $\mathrm{CHF}$ & $4.2(1.8-9.6) P=.0006$ & $8.9(3.0-26.9)$ & $2.4(0.7-8.5)$ & $4.5(1.7-12.1) P=.0029$ & $1.1(0.2-5.7)$ & $5.5(1.5-19.2)$ \\
\hline Urgent & $2.0(1.2-3.2) P=.0042$ & $2.3(1.0-5.2)$ & $1.7(0.9-3.1)$ & $2.3(1.2-4.2) P=.0089$ & $2.1(0.9-4.3)$ & $2.3(1.0-4.9)$ \\
\hline SVG to LAD & $2.2(1.1-4.4) P=.0168$ & $2.8(0.9-9.0)$ & $2.1(0.9-4.7)$ & $2.8(1.3-6.0) P=.0068$ & $3.6(0.5-8.9)$ & $2.7(1.1-6.8)$ \\
\hline Female sex & $1.4(0.8-2.6) P=.1932$ & $0.8(0.3-2.0)$ & $2.3(1.2-4.6)$ & $0.9(0.6-1.6) P=.2482$ & $0.7(0.3-1.6)$ & $2.5(1.1-5.8)$ \\
\hline $\mathrm{CRF}(\mathrm{cr}>2.0 \mathrm{mg} / \mathrm{dL})$ & $1.1(0.2-4.9) P=.9251$ & $0.8(0.4-1.1)$ & $4.4(1.3-15.5)$ & $3.8(0.6-9.0) P=.2571$ & $0.9(0.8-7.9)$ & $5.3(1.2-24.2)$ \\
\hline Previous AF & $1.6(0.4-2.6) P=.1932$ & $3.2(0.5-21.4)$ & $0.8(0.1-7.2)$ & $1.9(0.7-5.0) P=.2598$ & $9.0(1.7-45.8)$ & $1.7(0.5-6.2)$ \\
\hline Age $\geq 75$ y & $1.5(0.7-2.9) P=.4602$ & $2.9(0.9-8.7)$ & $1.0(0.4-2.6)$ & $2.4(1.1-5.1) P=.0223$ & $5.7(1.9-17.1)$ & $1.03(0.5-2.2)$ \\
\hline Diabetes & $1.4(0.8-2.4) P=.1803$ & - & - & $2.01 .1-3.7) P=.0320$ & - & - \\
\hline
\end{tabular}

$H R$, Hazard ratio; $C L$, confidence limit; $E F$, ejection fraction; $A M I$, acute myocardial infarction; $C H F$, chronic heart failure; $C R F$, chronic renal failure; $A F$, atrial fibrillation.

$0.4 \%, 94.9 \% \pm 0.9 \%$ in group D and $96.6 \% \pm 0.4 \%$ in group ND ( $P=.0155$, Figure 2$)$. The results of Cox analysis are also shown in Table 5 . Now diabetes is again a risk factor for increased incidence of cardiac deaths. Interestingly, the use of saphenous vein graft (SVG) on the left anterior descending artery (LAD) appeared as a new risk factor, emphasizing a direct effect of this graft on late cardiac mortality.

\section{Late Actuarial Survival of Patients Who Survived for 30 Days}

Five-year actuarial survival, with the exclusion of the first month, was $95.7 \% \pm 0.4 \%, 95.6 \% \pm 0.9 \%$ in group D and
$95.7 \% \pm 0.5 \%$ in group ND (Figure 3, $P=.3642$ ). Results of Cox analysis are shown in Table 6.

Freedom from cardiac death was $97.8 \% \pm 0.3 \%, 97.3 \%$ $\pm 0.8 \%$ in group D and $97.9 \% \pm 0.4 \%$ in group ND (Figure $4, P=.2389)$. Results of Cox analysis are also shown in Table 6. Diabetes was no longer a risk factor once patients who died in the first 30 days were excluded.

\section{Results According to Preoperative Treatment}

The preoperative treatment of diabetes did not affect early mortality (group OT, 18/596 [3.0\%]; group IT, 7/171 [4.1\%]). Five-year survival was also similar $(94.64 \% \pm$ $1.8 \%$ in group IT vs $92.0 \% \pm 1.3 \%$ in group OT, $P=$ 


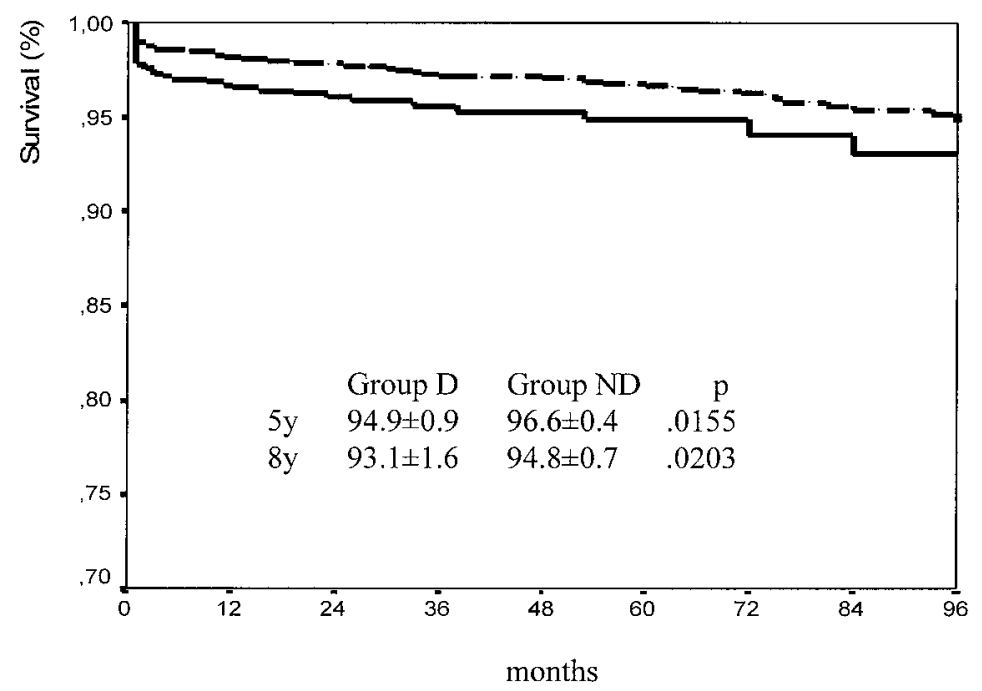

$\begin{array}{lccccccccc}\text { D group } & 767 & 656 & 495 & 363 & 274 & 176 & 117 & 94 & 82 \\ \text { ND group } & 2593 & 2279 & 1861 & 1520 & 1195 & 864 & 660 & 513 & 434\end{array}$

Figure 2. Five-year freedom from cardiac death (first month included): group D (solid line) versus group ND (dashed line).

TABLE 5. Cox analysis: Independent risk factors for increased mortality, any death, and cardiac deaths

\begin{tabular}{|c|c|c|c|c|c|c|c|}
\hline \multirow[b]{2}{*}{ Variable } & \multicolumn{4}{|c|}{ Any death } & \multicolumn{3}{|c|}{ Cardiac deaths } \\
\hline & $\begin{array}{r}\text { All patie } \\
\quad(95 \%\end{array}$ & $\begin{array}{l}\text { nts, HR } \\
\text { CL) }\end{array}$ & $\begin{array}{l}\text { Group D, HR } \\
\text { (95\%CL) }\end{array}$ & $\begin{array}{l}\text { Group ND, HR } \\
(95 \% \mathrm{CL})\end{array}$ & $\begin{array}{l}\text { All patients, HR } \\
(95 \% \mathrm{CL})\end{array}$ & $\begin{array}{l}\text { Group D, HR } \\
\text { (95\%CL) }\end{array}$ & $\begin{array}{l}\text { Group ND, HR } \\
(95 \% \mathrm{CL})\end{array}$ \\
\hline Age & $1.0(1.01-1.04)$ & $P=.0003$ & $1.0(0.97-1.04)$ & $1.04(1.01-1.06)$ & $1.0(1.0-1.05) P=.0061$ & $1.0(0.97-1.06)$ & $1.03(1.01-1.06)$ \\
\hline$E F \leq 35 \%$ & $2.3(1.5-3.5)$ & $P=.0001$ & $1.8(0.8-3.9)$ & $2.6(1.6-4.3)$ & $2.3(1.3-4.0) \quad P=.0025$ & $1.7(0.6-4.7)$ & $2.3(1.2-4.5)$ \\
\hline Previous AMI & $1.4(1.1-1.9)$ & $P=.0138$ & $1.2(0.7-2.2)$ & $1.5(1.1-2.1)$ & $1.2(0.8-1.8) \quad P=.2448$ & $1.4(0.7-2.8)$ & $1.2(0.8-1.8)$ \\
\hline CHF & $2.1(1.2-3.8)$ & $P=.0095$ & $4.5(1.9-10.5)$ & $1.6(0.7-3.5)$ & $1.9(0.8-4.1) \quad P=.1192$ & $1.6(0.4-7.1)$ & $2.1(0.8-5.4)$ \\
\hline $\mathrm{CRF}(\mathrm{cr}>2.0 \mathrm{mg} / \mathrm{dL})$ & $3.9(2.1-7.2)$ & $P<.0001$ & $1.0(0.1-1.3)$ & $5.6(2.9-10.8)$ & $5.8(2.8-12.0) P<.0001$ & $1.7(0.2-13.4)$ & $7.8(3.5-17.4)$ \\
\hline Urgent & $1.4(1.1-1.9)$ & $P=.0158$ & $2.1(1.2-3.5)$ & $1.3(0.9-1.8)$ & $1.6(1.1-2.3) \quad P=.0132$ & $2.4(1.3-4.6)$ & $1.4(0.9-2.2)$ \\
\hline Peripheral vasculopathy & $1.6(1.1-2.3)$ & $P=.0153$ & $1.9(1.0-3.6)$ & $1.4(0.8-2.3)$ & $1.2(0.9-2.0)$ & $1.1(0.5-2.8)$ & $1.2(0.6-2.3)$ \\
\hline SVG to LAD & $1.4(0.9-2.0)$ & $P=.0868$ & $1.8(0.9-3.4)$ & $1.3(0.8-2.0)$ & $2.0(1.3-3.2)$ & $1.9(0.8-4.7)$ & $2.0(1.2-3.4)$ \\
\hline Diabetes & $1.3(0.9-1.7)$ & $P=.1166$ & - & - & $1.6(1.1-2.3) \quad P=.0180$ & - & - \\
\hline
\end{tabular}

$H R$, Hazard ratio; $C L$, confidence limit; $E F$, ejection fraction; $A M I$, acute myocardial infarction; $C H F$, chronic heart failure; $C R F$, chornic renal failure.

$.1850)$, as was freedom from cardiac death after 5 years $(97.1 \% \pm 1.3 \%$ in group IT vs $94.4 \% \pm 1.1 \%$ in group OT, $P=.1225)$.

Analyzing the patients who survived 30 days, 5-year survival was not significantly better in group IT $(98.6 \% \pm$ $1.0 \%)$ than in group OT $(94.8 \% \pm 1.1 \%)$, even if Cox analysis did not confirm this hypothesis. Freedom from cardiac-related death was not different in either group $(99.4 \% \pm 0.6 \%$ in group IT vs $96.7 \% \pm 0.9 \%$ in group OT).

There were no statistically significant differences in short- or long-term mortality for diabetic patients treated perioperatively with insulin versus those who were not.
Results According to Perioperative Surgical Strategy Tables 7 and 8 show 10-year survival and 10-year freedom from cardiac death according to some technical variables used during the procedure. Even if there is an evident benefit at the univariate analysis in using extensive arterial grafting, the Cox analysis failed to confirm this hypothesis. Only the use of SVG on LAD was a risk factor for increased incidence of cardiac deaths with and without the exclusion of the first month (Tables 5 and 6).

\section{Discussion}

Because morbidity and mortality caused by ketoacidosis and infections have a low incidence, coronary artery disease 


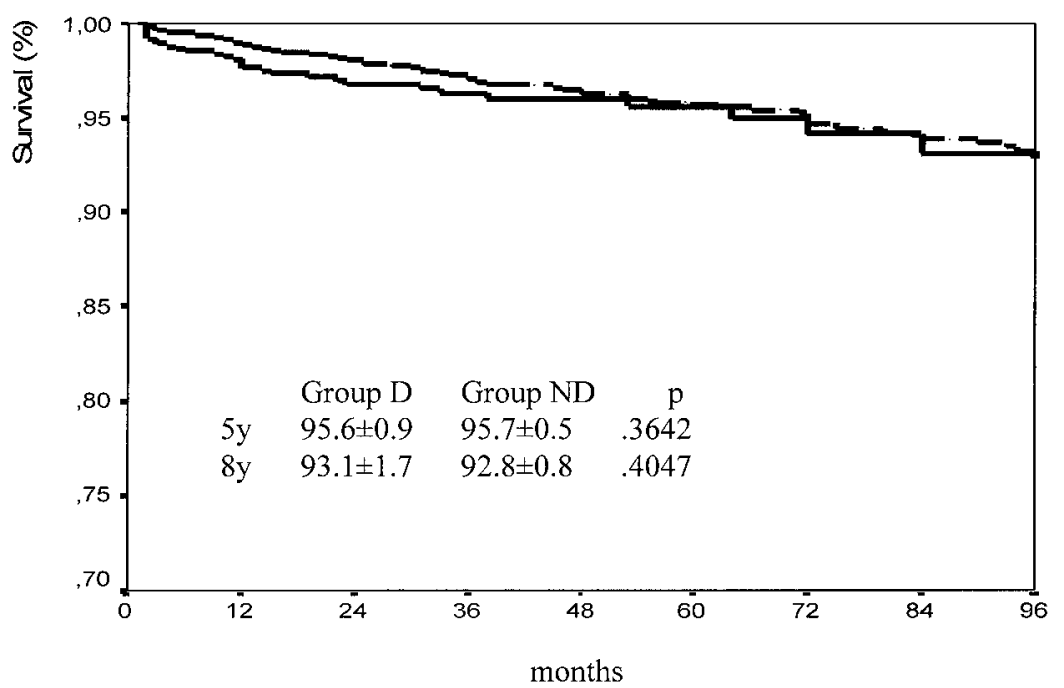

$\begin{array}{lllllllllr}\text { D group } & 742 & 656 & 495 & 363 & 274 & 176 & 117 & 94 & 82 \\ \text { ND group } & 2544 & 2279 & 1861 & 1520 & 1195 & 864 & 660 & 513 & 434\end{array}$

Figure 3. Five-year actuarial survival (first month excluded): group D (solid line) versus group ND (dashed line).

TABLE 6. Cox analysis: Independent risk factors for increased late mortality (first month excluded), all causes and cardiac causes

\begin{tabular}{|c|c|c|c|c|c|c|c|c|}
\hline \multirow{2}{*}{ Variable } & \multicolumn{4}{|c|}{ Any death } & \multicolumn{4}{|c|}{ Cardiac deaths } \\
\hline & $\begin{array}{r}\text { All patien } \\
(95 \% \mathrm{C}\end{array}$ & $\begin{array}{l}\text { ts, HR } \\
\text { CL) }\end{array}$ & $\begin{array}{c}\text { Group D, HR } \\
\text { (95\%CL) }\end{array}$ & $\begin{array}{c}\text { Group ND, HR } \\
\text { (95\%CL) }\end{array}$ & $\begin{array}{r}\text { All patien } \\
(95 \% \mathrm{C}\end{array}$ & $\begin{array}{l}\text { its, HR } \\
\mathrm{CL})\end{array}$ & $\begin{array}{l}\text { Group D, HR } \\
\text { (95\%CL) }\end{array}$ & $\begin{array}{c}\text { Group ND, HR } \\
\text { (95\%CL) }\end{array}$ \\
\hline Age & $1.03(1.01-1.05)$ & $P=.0025$ & $1.0(0.96-1.04)$ & $1.04(1.01-1.06)$ & $1.02(0.9-1.1)$ & $P=.0581$ & $1.0(0.94-1.05)$ & $1.03(0.98-1.07)$ \\
\hline$E F \leq 35 \%$ & $2.7(1.6-4.5)$ & $P=.0001$ & $2.9(1.1-7.7)$ & $2.7(1.5-5.0)$ & $2.8(1.4-5.8)$ & $P=.0033$ & $2.9(0.8-10.6)$ & $2.6(1.1$ \\
\hline Previous AMI & $1.5(1.0-2.1)$ & $P=.0327$ & $1.1(0.5-$ & $1.6(1.1-$ & $1.4(0.8-2.3)$ & $P=.1982$ & $1.7(0.6-4.8)$ & $1.2(0.7-2.3)$ \\
\hline $\mathrm{CRF}>2.0 \mathrm{mg} / \mathrm{dL}$ & $5.9(2.8-12.3)$ & $P=.0001$ & $3.7(0.5-28.4)$ & $6.9(3.1-15.3)$ & $11.1(4.7-26.1)$ & $P<.0001$ & $3.9(0.8-5.5)$ & $13.2(5.0-34.3)$ \\
\hline Peripheral vasculopathy & $1.7(1.1-2.8)$ & $P=.0226$ & $3.0(1.4-6.5)$ & $1.3(0.7-2.4)$ & - & & $2.0(0.7-6.2)$ & $0.9(0.3-2.4)$ \\
\hline SVG-LAD & $1.1(0.7-1.8)$ & $P=.5786$ & $1.1(0.4-3.2)$ & $1.1(0.7-1.9)$ & $1.8(1.0-3.1)$ & $P=.0484$ & $1.3(0.4-4.3)$ & $1.9(1.0-3.7)$ \\
\hline
\end{tabular}

$H R$, Hazard ratio; $C L$, confidence limit; $E F$, ejection fraction; $A M I$, acute myocardial infarction; $C R F$, chronic renal failure.

assumes a larger responsibility as a cause of death in diabetic patients. ${ }^{28,29}$ The overall prevalence of coronary disease is as high as $55 \%$ among adult diabetic patients compared with $2 \%$ to $4 \%$ for the general population. ${ }^{30}$ In a large autopsy study $91 \%$ of the patients with adult diabetes and no known coronary artery disease had severe narrowing of at least one major coronary artery, and 83\% had severe 2- or 3-vessel involvement. ${ }^{31}$ The relative risk of myocardial infarction is $50 \%$ greater in diabetic men and $150 \%$ greater in diabetic women. Similarly, diabetic men have sudden death $50 \%$ more often and diabetic women $300 \%$ more often than do their age-matched nondiabetic counterparts. ${ }^{32}$ The mortality for myocardial infarction is higher than in nondiabetic patients ${ }^{33,34}$ with $^{35}$ or without ${ }^{36,37}$ thrombolytic therapy. Furthermore, the presence of diabetes mellitus is an independent pre- dictor of cardiac mortality, which ranges from $26 \%$ to $62 \%$ in the first year after myocardial infarction and can reach $79 \%$ by 5 years. ${ }^{38,39}$

Diabetic patients with multivessel coronary disease who undergo myocardial revascularization, both surgical and interventional, are considered at high risk for early and late death. ${ }^{1-11}$ Because other reports were not in agreement with these findings, ${ }^{15-22}$ we tried to find a personal answer to this problem by analyzing our database, which included patients operated on during 12 years.

The analysis of 30-day mortality showed that diabetes is a univariate risk factor for higher early mortality, but multivariable analysis rejected this hypothesis. Analysis of a large cohort of patients in a New York State database found that diabetes was a risk factor in 2 different periods: 1992 to 1995 and 1996. ${ }^{11,12}$ This finding was confirmed by others. ${ }^{7,8}$ 


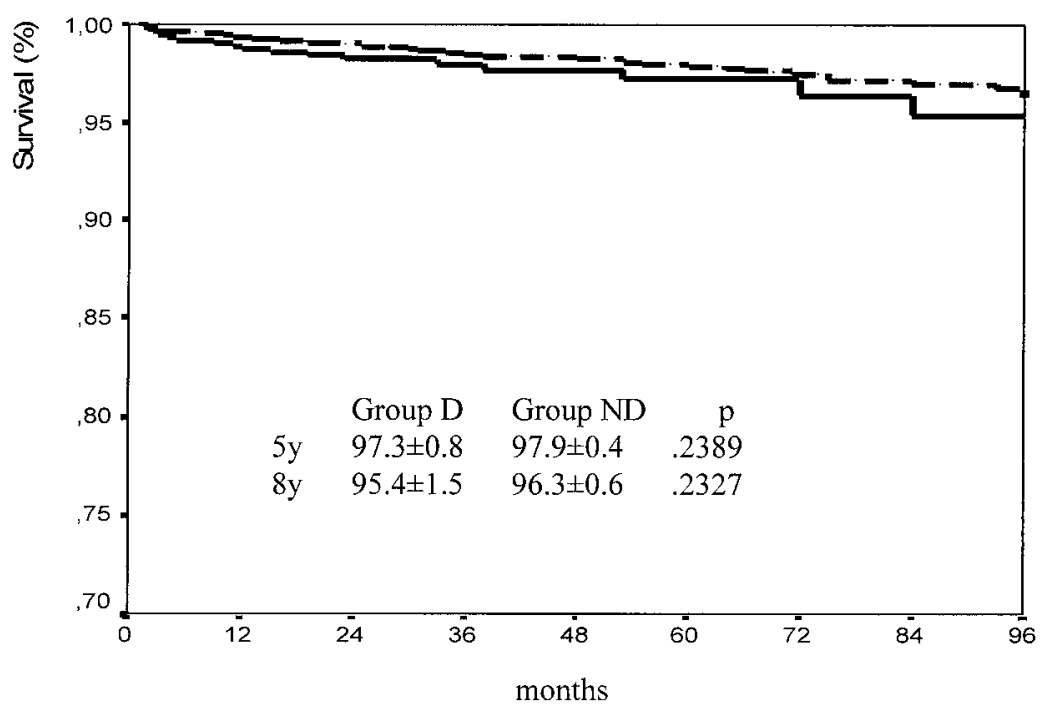

$\begin{array}{lccccccccc}\text { D group } & 742 & 656 & 495 & 363 & 274 & 176 & 117 & 94 & 82 \\ \text { ND group } & 2544 & 2279 & 1861 & 1520 & 1195 & 864 & 660 & 513 & 434\end{array}$

Figure 4. Five-year freedom from cardiac death (first month excluded): group D (solid line) versus group ND (dashed line).

TABLE 7. Ten-year (first month included) survival according to same surgical aspects (univariate analysis)

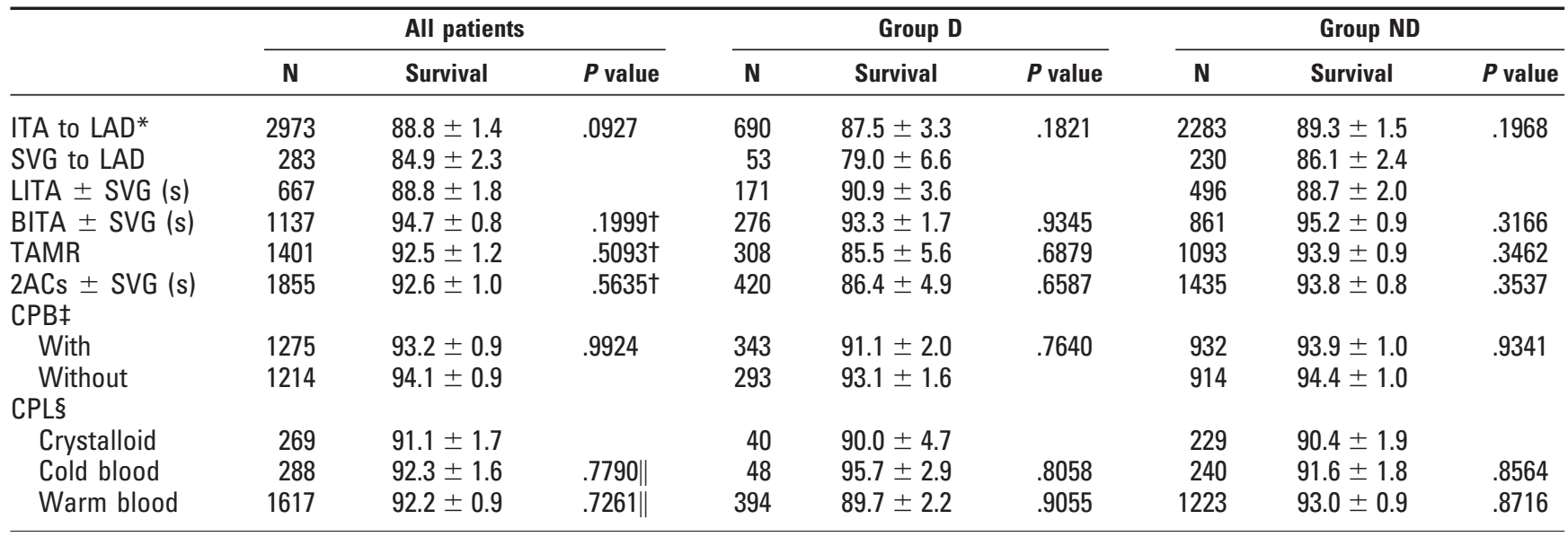

All intermittent antegrade; no statistical difference was present when comparing groups. ITA, Internal thoracic artery; BITA, bilateral internal thoracic artery; TAMR, total arterial myocardial revascularization; CPL, cardioplegia.

*With or without SVG, other arterial conducts, or both.

† $P$ value versus LITA \pm SVG(s).

†Five-year survival.

$\S$ Eight-year survival.

$\| P$ value versus crystalloid.

However, other reports failed to identify diabetes as a risk factor in the general population ${ }^{18-20,22}$ or in the elderly. ${ }^{21}$

In our opinion 30-day mortality is influenced by technical details more than by the disease itself. Even if no surgical aspect was able to influence the 30-day outcome in diabetic patients, some aspects allowed a reduction of mor- tality more in group D than in group ND. Use of SVG on LAD in group D was related to high mortality (4/53 [7.5\%]); on the contrary, when the left internal thoracic artery was used, the mortality showed a 2.6-fold reduction $(21 / 714$ [2.9\%]). The same aspect allowed a minor reduction in group ND (from $3.0 \%$ to $1.8 \%, 1.7$-fold). The huge 
TABLE 8. Ten-year (first month included) freedom from cardiac death according to same surgical aspects (univariate analysis)

\begin{tabular}{|c|c|c|c|c|c|c|c|c|c|}
\hline & \multicolumn{3}{|c|}{ All patients } & \multicolumn{3}{|c|}{ Group D } & \multicolumn{3}{|c|}{ Group ND } \\
\hline & $\mathbf{N}$ & Survival & $P$ value & $\mathbf{N}$ & Survival & $P$ value & $\mathbf{N}$ & Survival & $P$ value \\
\hline ITA to LAD* & 2973 & $93.8 \pm 1.0$ & .0041 & 690 & $90.5 \pm 3.3$ & .1954 & 2283 & $94.6 \pm 1.0$ & .0072 \\
\hline SVG to LAD & 283 & $88.3 \pm 2.1$ & & 53 & $82.3 \pm 6.5$ & & 230 & $89.5 \pm 2.1$ & \\
\hline LITA \pm SVG & 667 & $93.7 \pm 1.3$ & & 171 & $93.1 \pm 3.5$ & & 496 & $93.9 \pm 1.5$ & \\
\hline $\mathrm{BITA} \pm \mathrm{SVG}$ & 1137 & $97.6 \pm 0.5$ & $.0642 \dagger$ & 276 & $95.3 \pm 1.5$ & .5616 & 861 & $98.3 \pm 0.5$ & .0155 \\
\hline TAMR & 1401 & $93.7 \pm 2.3$ & $.1640 \dagger$ & 308 & $90.2 \pm 5.6$ & .5898 & 1093 & $94.4 \pm 0.9$ & .1077 \\
\hline $2 \mathrm{ACs} \pm \mathrm{SVG}$ & 1855 & $94.2 \pm 1.5$ & $.8697 \dagger$ & 420 & $91.1 \pm 3.6$ & .7140 & 1435 & $95.0 \pm 2.7$ & .1092 \\
\hline \multicolumn{10}{|l|}{ CPB } \\
\hline With & 1275 & $96.2 \pm 0.7$ & .3171 & 343 & $93.9 \pm 1.8$ & .2766 & 932 & $97.1 \pm 0.7$ & .1937 \\
\hline Without & 1214 & $95.8 \pm 0.9$ & & 293 & $95.3 \pm 1.4$ & & 921 & $96.0 \pm 1.0$ & \\
\hline \multicolumn{10}{|l|}{ CPL§ } \\
\hline Crystalloid & 269 & $93.2 \pm 1.5$ & & 40 & $90.0 \pm 4.7$ & & 229 & $94.7 \pm 1.3$ & \\
\hline Cold blood & 288 & $94.7 \pm 1.3$ & $.5298 \|$ & 48 & $97.8 \pm 2.2$ & $.5543 \|$ & 240 & $94.1 \pm 1.5$ & $.6785 \|$ \\
\hline Warm blood & 1617 & $95.1 \pm 1.1$ & $.5588 \|$ & 394 & $94.0 \pm 1.5$ & $.4097 \|$ & 1223 & $95.6 \pm 1.2$ & $.7456 \|$ \\
\hline
\end{tabular}

All intermittent antegrade; no statistical difference was present when comparing groups. ITA, Internal thoracic artery; BITA, bilateral internal thoracic artery; TAMR, total arterial myocardial revascularization; $C P B$, cardiopulmonary bypass; $C P L$, cardioplegia.

${ }^{*} \pm S V G$, other arterial conducts, or both.

† $P$ value versus $\mathrm{LITA} \pm \mathrm{SVG}(\mathrm{s})$.

†Five-year survival.

$\S$ Eight-year survival.

$\| P$ value versus crystalloid.

application of the non-CPB strategy reduced the early mortality from $4.0 \%$ to $2.0 \%$ in group D (2-fold) and from $2.1 \%$ to $1.5 \%$ in group ND (1.4-fold). Cumulating all these small and apparently not influential improvements, diabetic patients are no longer at higher risk for 30-day mortality.

However, if only cardiac mortality in considered, diabetes appears to have a significant influence on early outcome because the relative incidence of cardiac deaths is higher in group D than in group ND. The anatomic aspect of the disease (diffuse coronary disease, small vessels, and diffuse calcifications) can explain a higher cardiac mortality.

Late survival, including 30-day mortality, showed, at univariate analysis, that diabetes was a risk factor, but the Cox analysis did not confirm this finding. Excluding 30-day mortality, diabetes was not a risk factor at either univariable or multivariable analysis.

When only cardiac deaths were considered, diabetes was a risk factor both at the univariable and multivariable analysis for increased early cardiac mortality and for reduced life expectancy as a result of cardiac death. However, when the analysis included only the patients who survived 30 days, diabetes disappeared as a risk factor both at univariable and multivariable analysis, showing that the influence of diabetes on survival without cardiac death is mainly expressed during the first postoperative month.

Other reports show clearly that diabetes is an important risk factor for late survival. Herlitz and colleagues ${ }^{6}$ showed that real 2-year survival was $86.1 \%$ in diabetic and $93.5 \%$ in nondiabetic patients $(P<.0001)$. At the multivariable anal- ysis, diabetes had a relative risk of 1.7. Morris and coworkers ${ }^{40}$ reported a 5-year survival of $80 \%$ in diabetic patients and $91 \%$ in nondiabetic patients and an 8-year survival of $66 \%$ and $84 \%$, respectively $(P<.0001)$. Diabetes was an independent risk factor with a $P$ value of .0001 . Smith and associates ${ }^{41}$ showed a 15 -year survival of $40 \%$ in diabetic and $60 \%$ in nondiabetic patients. Diabetes was a strong independent risk factor $(P=.0001)$ but only in the late phase ( $>1$ year after the operation). The same findings were confirmed by other studies. ${ }^{8-10}$ Diabetes was rarely not recognized as an independent risk factor for late survival, often only in subgroups of patients. ${ }^{19}$ When freedom from cardiac death was considered, diabetes was again a risk factor. Pick and colleagues ${ }^{9}$ found that diabetes was an independent risk factor both for 10-year overall (risk hazard ratio, 2.94) and cardiac (hazard ratio, 1.73) mortality. Globally, diabetes was a risk factor in the late period, starting the first year after the procedure.

Our findings are in contrast with those in many of the published studies on this topic. Logically, if diabetic patients in the general population have higher mortality than nondiabetic patients as a result of cardiac causes, it is reasonable that a diabetic patient who undergoes myocardial revascularization has a life expectancy better than that of a nonoperated patient and similar to that of a nondiabetic patient. Even if diabetes was a risk factor for higher cardiac 5 -year mortality, this finding was the consequence of a higher early cardiac mortality ( $2.2 \%$ in group D vs $1.1 \%$ in group ND, $P=.016$ ) and not of a late higher mortality. 
In fact, survival from surgical intervention was not found to be different for diabetic versus nondiabetic patients who survived to 1 month. The preoperative treatment of diabetic patients did not influence the outcome. Surprisingly, insulin-treated patients showed a high long-term survival ( $94.6 \%$ by 5 years).

Perhaps long-term treatment with insulin, because antidiabetic centers are widely diffused, can better control hyperglycemia, lowering the complication rate in the long term. However, the sample size is small, and definitive conclusions can not be drawn.

Our analysis was not able to show improvement related to any technical aspect during the operation. Early and late outcomes of diabetic patients were not influenced by use of SVG on LAD. Conversely, nondiabetic patients were influenced by use of SVG on LAD only in the analysis of freedom from cardiac death, both early and late, with or without the inclusion of the first month.

This is in contrast with other reports ${ }^{9,15,42}$ that show a better outcome in diabetic patients if a single or a double internal thoracic artery is used. We were not able to find any benefit with the use of bilateral internal thoracic arteries in nondiabetic patients, and the use of left internal thoracic arteries to LAD demonstrated an advantage only for cardiac deaths. This is not easy to explain. We think that the patency rate of the SVG in the 1990s is perhaps better than the patency rate of the SVG in the 1980s. Worldwide use of antiplatelet agents, as well as statins, can contribute to this theoretic benefit. Moreover, the mean follow-up in our series is shorter than in other reports,,${ }^{9,42}$ and some authors ${ }^{40}$ did not use a multivariable analysis to demonstrate their hypothesis.

The similar late outcome in diabetic and nondiabetic patients after a mean follow-up of 50 months suggests that the effect of surgical intervention in diabetic patients is striking. The huge cardiovascular mortality is highly reduced after myocardial revascularization, and the risks of myocardial infarction with the related mortality are also reduced. However, the incidence of cardiac deaths remains higher than that in nondiabetic patients, although this finding is limited to the first 30 days after the operation. The price to pay for diabetes seems today smaller than in the past.

One must take care with interpretations of subgroup analyses. Lack of statistical significance might simply be a lack of statistical power because of the reduced sample size. Statistical significance might be due to spurious results, which are expected with multiple comparisons.

In multivariable models one must remember that not only the factors in the model but the factors in the univariable analyses were considered. Therefore any borderline statistical result should be considered especially exploratory.

\section{References}

1. Alderman E, Bourassa M, Brooks MM, at al. Influences of diabetes on 5 -year mortality and morbidity in a randomized trial comparing CABG and PTCA in patients with multivessel disease. The Bypass Angioplasty Revascularization Investigation (BARI). Circulation. 1997;96:1761-9.

2. Barsness GW, Peterson ED, Magnus Ohman E, et al. Relationship between diabetes mellitus and long-term survival after coronary bypass and angioplasty. Circulation. 1997;96:2551-6.

3. Alderman EL, Corley SD, Fisher LD, et al. Five- year angiographic follow-up of factor associated with progression of coronary artery disease in the Coronary Artery Surgery Study (CASS). J Am Coll Cardiol. 1993;22:1141-54.

4. Fietsam RJ, Basset J, Glover JL. Complication of coronary artery surgery in diabetic patients. Am Surg. 1996;57:551-7.

5. Cohen Y, Raz I, Gideon M, Mozes B. Comparison of factors associated with 30-day mortality after coronary artery bypass grafting in patients with versus without diabetes mellitus. Am J Cardiol. 1998; 81:7-11.

6. Herlitz J, Wognsen BG, Emanuelsson H, et al. Mortality and morbidity in diabetic and nondiabetic patients during a 2-year period after coronary artery bypass grafting. Diabetes Care. 1996;19:698-703.

7. Weintraub WS, Stein B, Gebhart SSP, et al. The impact of diabetes on the initial and long term outcome of coronary artery bypass surgery [abstract]. Circulation. 1995;92(suppl I):643-4.

8. James TW, Quinton HB, Birkmeyer JD, et al. Diabetes and coronary artery bypass graft surgery risk [abstract]. Circulation. 1996;94(suppl I):412.

9. Pick AW, Orszulak TA, Anderson BJ, et al. Single versus bilateral internal mammary artery graft: 10-year outcome analysis. Ann Thorac Surg. 1997;64:599-605.

10. Accola KD, Jones EL, Craver JM, et al. Bilateral mammary artery grafting: avoidance of complications with extended use. Ann Thorac Surg. 1993;56:872-9.

11. Hannan EL, Kilburn H, Racz M, et al. Improving the outcomes of coronary artery bypass surgery in New York State. JAMA. 1994;271: 761-6.

12. Koegh BE, Kinsman R. Database report 1998. In: National adult cardiac surgical data. Society of Cardiothoracic Surgery of Great Britain and Ireland. www.scts.org/sctsdbr98.pdf.

13. Weintraub WS, Stein B, Kosinski, A et al. Outcome of coronary artery bypass surgery versus coronary angioplasty in diabetic patients with multivessel coronary artery disease. J Am Coll Cardiol. 1998;31:10-9.

14. Detre KM, Guo P, Holubkov R, et al. Coronary revascularization in diabetic patients. A comparison of the randomized and observational components of the Bypass Angioplasty Revascularization Investigation (BARI). Circulation. 1999;99:633-40.

15. Hirotani T, Kameda T, Kumamoto T, et al. Effects of coronary artery bypass grafting using internal mammary arteries for diabetic patients. J Am Coll Cardiol. 1999;34:532-8.

16. Clement R, Rousou JA, Engelman RM, et al. Perioperative morbidity in diabetics requiring coronary artery bypass surgery. Ann Thorac Surg. 1988;46:321-3.

17. Kurlansky PA, Dorman MJ, Galbut DL, et al. Bilateral internal mammary artery grafting in women: a 21-year experience. Ann Thorac Surg. 1996;62:63-9.

18. Berreklouw E, Schonberger JP, Bavinck JH, et al. Similar hospital morbidity with the use of one or two internal thoracic arteries. Ann Thorac Surg. 1994;57:1564-72.

19. Gardner TJ, Greene PS, Rykiel MF, et al. Routine use of the left internal mammary artery graft in the elderly. Ann Thorac Surg. 1990; 49:188-94.

20. Horvath KA, DiSesa VJ, Peigh PS, et al. Favorable results of coronary artery bypass grafting in patients older than 75 years. $J$ Thorac Cardiovasc Surg. 1990;99:92-6.

21. Wei He G, Acuff TE, Ryan WH, et al. Determinants of operative mortality in elderly patients undergoing coronary artery bypass grafting. J Thorac Cardiovasc Surg. 1994;108:73-81.

22. Higgins TL, Estafanous FG, Loop FD, et al. Stratification of morbidity and mortality outcome by preoperative risk factors in coronary artery bypass patients. JAMA. 1992;267:2344-8. 
23. Salerno TA, Houck JP, Barrozo CA, et al. Retrograde continuous warm blood cardioplegia: a new concept in myocardial protection. Ann Thorac Surg. 1991;51:245-74.

24. Buffolo E, Silva de Andrade JC, Rodrigues Branco JN, et al. Coronary artery bypass surgery without cardiopulmonary bypass. Ann Thorac Surg. 1996;61:63-6.

25. Calafiore AM, Di Giammarco G, Teodori G, et al. Recent advances in multivessel coronary grafting without cardiopulmonary bypass. Heart Surg Forum. 1998;1:20-5.

26. Calafiore AM, Di Giammarco G. Complete revascularization with three or more arterial conduits. Semin Thorac Cardiovasc Surg. 1996; 8:15-23.

27. Loop FD, Lytle BW, Cosgrove DM, et al. Influence of the internalmammary-artery graft on 10-year survival and other cardiac events. N Engl J Med. 1986;334:216-9.

28. Abbot RD, Donahue RP, Kannel WB, et al. The impact of diabetes on survival following myocardial infarction in men vs women: the Framingham Study. JAMA. 1988;260:3456-60.

29. Stamler J, Vaccaro O, Neaton JD, et al. Diabetes, other risk factors, and 12 year cardiovascular mortality from men screened in the Multiple Risk Factor Intervention Trial. Diabetes Care. 1993;16:434-44.

30. Fein F, Scheuer J. Heart disease in diabetes mellitus: theory and practice. In: Rifkin H, Potre D Jr, editors. New York: Elsevier; 1990. p. 812-23.

31. Feid FS. Heart disease in diabetes. Cardiovasc Rev Rep. 1982;3:877-93.

32. Waller B, Palumbo P, Roberts W. Status of the coronary arteries at necropsy in diabetes mellitus with onset after age 30 years. Am J Med. 1980;69:498-506.

33. Jacoby RM, Nesto RW. Acute myocardial infarction in the diabetic patients: pathophysiology, clinical course and progress. J Am Coll Cardiol. 1992;20:736-44.
34. Nesto RW, Philips RT, Kett KG, et al. Angina and exertional myocardial ischemia in diabetic and non diabetic patients: assessment by thallium scintigraphy. Ann Intern Med. 1988;108:170-5.

35. Barbash GI, White HD, Modan M, et al. Significance of diabetes mellitus in patients with acute myocardial infarction receiving thrombolytic therapy. J Am Coll Cardiol. 1993;22:707-13.

36. Rytter L, Troelsen S, Beck-Nielsen H. Prevalence and mortality of acute myocardial infarction in patients with diabetes. Diabetes Care. $1985 ; 8: 230-4$

37. Stone PH, Muller JE, Hartwell T, et al. The effect of diabetes mellitus on prognosis and serial left ventricular function after acute myocardial infarction: contribution of both coronary disease and diastolic left ventricular dysfunction to adverse prognosis. J Am Coll Cardiol. 1989;14:49-57.

38. Smith JW, Marcus F, Serokman R. Prognosis of patients with diabetes mellitus after acute myocardial infarction. Am J Cardiol. 1984;54:71821.

39. Schechtman K, Capone R, Kleiger R, et al. Differential risk pattern associated with 3 month as compared with 3-12 month mortality and reinfarction after non-Q wave myocardial infarction. J Am Coll Cardiol. 1990;15:940-7.

40. Morris JJ, Smith LR, Jones RH, et al. Influence of diabetes and mammary artery grafting on survival after coronary bypass. Circulation. 1991;84(suppl III):275-84.

41. Smith RL, Harrell FE, Rankin S, et al. Determinants of early versus late cardiac death in patients undergoing coronary artery bypass graft surgery. Circulation. 1991;84(suppl III):245-53.

42. Lytle BW, Blackstone EH, Loop FD, et al. Two internal thoracic artery grafts are better than one. J Thorac Cardiovasc Surg. 1999;117: 855-72.

See appendix on page 154. 


\section{APPENDIX. List and definition of variables}

\begin{tabular}{|c|c|}
\hline \multicolumn{2}{|l|}{ Preoperative } \\
\hline Age & Continuous (y) \\
\hline Age $\geq 75$ y & Dichotomous \\
\hline Sex & Dichotomous \\
\hline Body weight & Kilograms \\
\hline History of hypertension & $\begin{array}{l}\text { Need of medical treatment }\left(\mathrm{Ca}^{2+} \text { blockers, } \beta \text {-blockers, angiotensin-converting }\right. \\
\text { enzyme inhibitors) }\end{array}$ \\
\hline History of smoking & More than 10 cigarettes a day smoked at least for $10 \mathrm{y}$ \\
\hline Hypercholesterolemia & Historical or at-present cholesterol value $>200 \mathrm{mg} / \mathrm{dL}$ \\
\hline Chronic renal failure & Creatinine value $>2.0 \mathrm{mg} / \mathrm{dL}$ \\
\hline Chronic hepatic failure & Bilirubin value $>2.0 \mathrm{mg} / \mathrm{dL}$ \\
\hline Chronic obstructive pulmonary disease & $\begin{array}{l}\mathrm{FEV}_{1} \text { less than } 75 \% \text { of predicted value, air } \mathrm{P}_{2} \text { lower than } 60 \mathrm{~mm} \mathrm{Hg} \text { or chronic } \\
\text { medical treatment }\end{array}$ \\
\hline Unstable angina & Presence of angina at rest, stable angina with worsening pattern, or de novo angina. \\
\hline Chronic heart failure & Heart failure in the history or at the present admission without angina \\
\hline Acute myocardial infarction $<24 \mathrm{~h}$ & Acute myocardial infarction 24 hours before surgical intervention \\
\hline Preoperative intra-aortic balloon pump & Use of intra-aortic balloon pump to stabilize unstable angina \\
\hline Previous atrial fibrillation & Dichotomous \\
\hline Not elective operation & $\begin{array}{l}\text { Any condition (eg, unstable angina, cardiogenic shock, critic left main stenosis) that } \\
\text { avoids discharge from the hospital }\end{array}$ \\
\hline Diabetes & Medical treatment for hyperglycemia at rest \\
\hline Insulin treatment & Insulin-dependent diabetes \\
\hline Oral treatment & Diabetes on oral treatment \\
\hline Ventricular arrhythmia & In history or requiring medical treatment at this admission \\
\hline Peripheral vasculopathy & $\begin{array}{l}\text { Symptoms or angiographic or echocardiographic evidence of dilation or reduction of } \\
\text { flow (stenosis or occlusion) of any artery, with the exclusion of carotid arteries }\end{array}$ \\
\hline Carotid disease & $\begin{array}{l}\text { Presence of a fibrocalcific plaque with a stenosis } \geq 50 \% \text { or of a soft plaque } \\
\text { conditioning any degree of stenosis }\end{array}$ \\
\hline Previous CVA & History of previous CVA with or without persistent neurologic defect \\
\hline Previous acute myocardial infarction & Electrocardiographic sign of myocardial infarction or documented non- 0 infarction \\
\hline Left main stem lesion & Stenosis $\geq 50 \%$ \\
\hline Ejection fraction & Continuous \\
\hline Ejection fraction $\leq 35 \%$ & Dichotomous \\
\hline Nitroglycerin e.v. & Need of nitroglycerin e.v. at the admission in operating room \\
\hline \multicolumn{2}{|l|}{ Perioperative } \\
\hline Use of CPB & Dichotomous \\
\hline Normothermic perfusion & Perfusion temperature $\geq 34^{\circ} \mathrm{C}$ \\
\hline Use of SVG on LAD & Dichotomous \\
\hline Use of bicaval internal thoracic artery & Dichotomous \\
\hline Use of only arteries & Dichotomous \\
\hline Simultaneous carotid surgery & Dichotomous \\
\hline Untouchable ascending aorta & $\begin{array}{l}\text { Severe atherosclerotic or calcified aortic wall not eligible for clamping or } \\
\text { manipulation detected before the operation or when the chest was open }\end{array}$ \\
\hline
\end{tabular}

